Nidia Vincent

\title{
El cuerpo que ríe: dinámicas de la comicidad teatral
}

En "El teatro y la peste", Antonin Artaud expuso que según San Agustín la acción destructora de la peste semeja la del teatro: la primera lleva hasta la muerte sin acabar con los órganos, y el segundo provoca en el espíritu - lo mismo de los individuos que de los pueblos- misteriosas y peligrosas alteraciones.

El teatro tiene la capacidad de perturbar, de transformar, porque el espectador se entrega a la escena y a través de la percepción de dos sentidos básicos, la vista y el oído, acepta como una realidad momentánea la magia del escenario. Esta capacidad del arte de sustituir la verdad por la ficción hasta conducirnos a estados catárticos de risa o de llanto está íntimamente relacionada con la forma de operar de la percepción humana.

Cuando vamos al teatro o al cine somos plenamente conscientes de que estamos ante una imitación de la vida; sin embargo nuestro "espíritu" acepta este evento como si fuese verdadero, y "vivimos" lo acontecido. La intensidad de una escena puede ser tal que pase a formar parte de nuestra experiencia de vida y en incontables ocasiones cuando la memoria nos la devuelve por alguna asociación, la mente duda si pertenece a lo real o es una honda vivencia de otra índole como los 
sueños, la imaginación, la ficción, el delirio. Esto se acentúa en el teatro, en donde una puesta en escena se verifica ante nuestros sentidos y son éstos los que perciben lo que de hecho "está sucediendo". El teatro es pues una realidad para hombres de carne y hueso que actúan en un espacio y un tiempo específicos (no son las hojas de un libro, ni un lienzo, ni metal, ni la proyección de un celuloide). Los sentidos lo reciben, la emoción lo constata, toca a otros procesos mentales darle su sustancia específica.

Si concedemos que la representación teatral establece una comunicación peculiar entre la obra y su auditorio, y creemos que modifica al propio espectador en cuanto testigo e intérprete de las acciones que ocurren para él desde el escenario, se vuelve necesario dirigir nuestra atención hacia la recepción de los procedimientos teatrales. El teatro transmite ideas y lleva a la reflexión, al juicio, pone en acción el pensamiento que ve la lógica de las tramas y de las conductas, a la vez que alcanza las emociones.

El presente trabajo surgió de la inquietud de explicarme por qué cuando vemos una obra cómica reímos. ¿Qué origina la sonrisa o la carcajada?

En el teatro cómico, fársico o tragicómico asistimos a la suma de todos los aspectos de la comicidad: presenciamos una situación graciosa, escuchamos parlamentos en los que caben chistes, ironías, albures, insultos, bajezas, juegos de palabras, frases ingeniosas; y además vemos encarnados a tipos cómicos o fársicos, cuyos tropiezos, defectos, desajustes e inferioridad se exhiben ante nuestros ojos en el cuerpo intencionalmente torpe del comediante.

El dramaturgo debe crear la situación divertida, dar con el lenguaje apropiado que prepare y apunte hacia el tono correcto y debe dar vida a personajes que sufrirán el conflicto y padecerán las consecuencias de su proceder. Deberá tender entre el espectador y la escena sutiles lazos que desembocarán en bur- 
la, en vergüienza, en tensión, en asco, en horror, a veces en contradictoria desolación que no conduce al llanto sino a la risa.

$\mathrm{El}$ autor de comedias escribe desde un sano escepticismo, desde la duda reflexiva que evita cualquier rigidez y estatismo, pues considera que el mundo está en movimiento y todo es relativo y sujeto de cambio. Requiere de una gran capacidad lúdica, de un amplio y flexible manejo del lenguaje, de un refinamiento tal en la conformación de sus tramas que le permita construir un mecanismo vital.

Para Eric Bentley ${ }^{1}$ la dinámica de la comedia es un continuo artificio que permite sobreponerse al sufrimiento a través del humor. Así, el autor cómico parte del dolor pero lo trasciende para arribar a un estado de regocijo. "A pesar de todo, me río", dice el escritor de comedias. El tono, y no el tema, es lo que debe conducir a su espectador a una relación confiada y placentera, para presenciar su propio absurdo con una distancia tal que pueda reír de sí mismo.

\section{El cuerpo que ríe}

Obligado es precisar que risa y humor o sentido del humor no son lo mismo. El humor o lo cómico pueden dar como resultado la risa; y es quien posee sentido del humor quien disfruta de lo cómico o humorístico. Un humorista es quien posee sentido del humor e ingenio para elaborar un chiste, parodiar, escribir una ironía o describir un hecho gracioso; y posee sentido del humor quien puede ver lo cómico de la vida y desde esta perspectiva vivirla con menos gravedad. El humor es una manifestación de la cultura y cambia en los distintos grupos sociales, raciales. Suele hablarse de humor inglés, judío, mexicano.

\footnotetext{
${ }^{1}$ Cfr. La vida del drama, Paidós, Buenos Aires, 1964.
} 
Muchos estudios psicológicos asocian el humor a la personalidad, y muy concretamente a la madurez de la misma. Quienes poseen sentido del humor (que no humorismo) son capaces de relativizar lo mismo el éxito que el fracaso; es un estado de ánimo ecuánime, una inalterabilidad que da su real medida a las cosas. No tienden a la depresión ni a la euforia. ${ }^{2}$

La palabra latina humor fue por largo tiempo un término científico, con traducción a todas las lenguas occidentales. Etimológicamente proviene de humus, humedad. El Diccionario de la Real Academia Española nos remite a dos sentidos: sustancia fluida o disposición del carácter, ninguno de los cuales se asocia a lo gracioso. Por el contrario, en la edición de 1771 de la Enciclopedia Británica, el vocablo ya está asociado al wit (ingenio).

Cuatrocientos años antes de Cristo, Hipócrates se opuso a la interpretación teológica de las enfermedades, y se basó en los cuatro elementos y su relación con sendos humores: bilis, sangre, cólera y flema. ${ }^{3}$ Posteriormente Galeno dirá que las diferentes combinaciones de estos fluidos determinan los temperamentos con sus respectivas características físicas y mentales y predisposiciones muy específicas. El individuo ideal sería aquel en quien se diera la mezcla proporcional de los cuatro humores.

\footnotetext{
${ }^{2}$ Garanto Alós explica: "Es el estado de ánimo, más o menos persistente y estable, que baña equilibradamente los sentimientos, emociones, estados de ánimo o corporales surgentes del contacto del individuo (corporalidad y psique) con el medio ambiente y que capacita al individuo para, tomando la distancia conveniente, relativizar críticamente toda clase de experiencias afectivas que le polaricen, bien sea hacia situaciones eufóricas bien sea hacia situaciones depresivas. Temple afectivo, tono vital que hace capaz al individuo de 'reírse — relativizarde sí mismo y reírlo — relativizarlo todo - a pesar de todo', afirmando la vida ejerciéndola seriamente”. Del libro Psicología del humor, p. 61.

3 Al elemento tierra correspondió la bilis negra, con propiedades como la frialdad y la sequedad, relacionadas con el temperamento del melancólico; el aire, como la sangre, tiene calor y humedad y se relacionó con el temperamento sanguíneo; el colérico se asemeja al fuego, caluroso y seco, y su correspondiente es la bilis amarilla, y por último en el flemático dominaba la flema asociada al agua, y será por ello frío y húmedo.
} 
En Enrique V, obra escrita por Shakespeare entre 1598 y 99, el personaje cómico Nym emplea por vez primera la palabra humor con el sentido de tontería o sinsentido. Pero fue otro dramaturgo inglés, Ben Jonson, que al utilizar de manera cómica los humores unió de manera indisoluble la semántica del vocablo humor a lo cómico. Jonson concibió la comedia como un teatro de caracteres, en donde los humores determinarían la definición de sus tipos: el colérico, el impulsivo, el atrabilario, el flemático y sus combinaciones intermedias. Every man in his humour (1598) y Every man out of his humour (1599) son ejemplos de este género pero también de una aguda observación de los hombres, pues encuentra que tanto la excentricidad como el comportamiento normal se derivan de algunos rasgos dominantes de la personalidad. ${ }^{4}$

Sabemos que durante la Edad Media la capa más radical de la jerarquía eclesiástica satanizó a la risa y a los mimos. ${ }^{5}$ No obstante, el carnaval, los juegos de escarnio y la fiesta fueron prácticas comunes imposibles de extirpar, pues su remotísimo origen en las fiestas agrarias responde a una sabiduría armoniosa que veía en ese desorden del "mundo al revés" una manera natural de regular el cuerpo social y dar salida a sus instintos. Según Bajtín, durante el Renacimiento la risa fue una de las formas fundamentales de expresión, pero durante los siglos XVII y XVIII se produjo un empobrecimiento y falsificación de los ritos y espectáculos carnavalescos. Sin embargo éstos

\footnotetext{
${ }^{4}$ Dos siglos después, Richard B. Sheridan escribiría para los actores del teatro Drury Lane su School for Scandal (1777): comedia de caracteres en la que personajes como Teazle, Surface, Bumper, Creeles, Snake y Candour ponen en riesgo el matrimonio de un viejo y una niña por sus hipocresías y murmuraciones.

${ }^{5}$ En la novela El nombre de la rosa, Umberto Eco puso este pensamiento en Jorge, el viejo y ciego bibliotecario de la abadía, con diálogos como éste: "No todo lo que es propio del hombre es necesariamente bueno. La risa es signo de estulticia. El que ríe no cree en aquello en lo que ríe, pero tampoco lo odia. Por tanto, reírse del mal significa no estar dispuesto a combatirlo, reírse del bien significa desconocer la fuerza del bien, que se difunde por sí sola.”
} 
nunca desaparecieron del todo, pues el principio carnavalesco es indestructible.

Hoy la risa y el humor son vistos como elementos intrínsecos a la naturaleza humana. Son benéficos, catárticos, curativos; válvula de escape para la violencia y el descontento de los pueblos; ejercicio inteligente y audaz de la crítica; mero entretenimiento que se frecuenta desde la infancia; eficaz recurso para la distracción y satisfacción de las masas, etc. Los medios más característicos del siglo xx, la radio, la televisión, el cine, el video, los discos, los casetes, los libros y las revistas dedican buena parte de su espacio a obras humorísticas. El hombre contemporáneo consume a gran escala estos productos y está dispuesto a pagar por reír.

Llegamos aquí a un punto de larga y compleja descripción. Me refiero al fenómeno de la risa. ¿Qué es? ¿Cómo se logra? ¿De qué reímos?

La risa es un alivio, es una liberación, es una falta de respeto: ridiculiza y relativiza la verdad del hombre y su cosmos, de su razón y su espíritu, de su creador y aún de su propia muerte o trascendencia. La risa nos aligera. ¿Quién no quiere reír?

Para Demócrito la risa era propia del hombre iluminado y maduro, reflejo de su visión unitaria del mundo. Para Hipócrates, la alegría era una práctica terapéutica, y esta idea fue muy aceptada durante el Renacimiento, tal como lo consigna Rabelais en su prólogo del libro IV, dirigido al Cardenal de Chatillon, para continuar con su Gargantúa:

...diariamente he sido y soy estimulado, requerido e importunado por grandes personajes para continuar las mitologías pantagruélicas, alegando que muchas gentes lánguidas, enfermas, disgustadas y desoladas habían engañado a su males con su lectura, pasado el tiempo gozosamente y recibido alegría y nuevo consuelo. ${ }^{6}$

\footnotetext{
${ }^{6}$ François Rabelais, Gargantúa y Pantagruel, p. 535.
} 
El clérigo y erudito inglés, Robert Burton (1577-1640), escribió en 1621 Anatomy of Melancholy, uno de los primeros textos de psiquiatría del que tenemos noticia, en el que afirmó que la risa era una medida curativa contra el mal llamado melancolía.

El estudio del funcionamiento de los hemisferios cerebrales ha aportado nueva información sobre el buen humor y la risa. Ahora se sabe que primero se registra actividad en el hemisferio izquierdo, el encargado del pensamiento lógico y analítico; y después se activa el hemisferio derecho, antes de que se manifieste la risa. En el acto de reír, hay impulsos en las áreas sensorimotoras y en los circuitos límbicos encargados del control hipotalámico del sistema autónomo. La medicina actual confiere a la risa propiedades terapéuticas para enfermedades específicas y conoce la forma en que ésta actúa en los pacientes. ${ }^{7}$

Existe la risa provocada por el estímulo físico de las cosquillas, reacción propia de los primates superiores. Muy distinta es la risa nerviosa que traduce la defensa de los centros cerebrales superiores contra la absurdidad del mundo; y otra más es la producida por un chiste, una broma, una situación cómica real o artificialmente producida por la ficción.

Con la risa el cuerpo se trastoca: unas francas carcajadas aflojan los músculos de la cara; participan las cuerdas vocales y la glotis; los ojos se aprietan o se abren desmesuradamente; se activan los músculos de cuello y abdomen. Cuando la hila-

\footnotetext{
${ }^{7}$ Que activa los músculos y la respiración es evidente, pero lo que la ciencia ha comprobado es que también los sistemas inmunológico, endocrino, digestivo, cardiovascular, nervioso central y autónomo se estimulan. De ahí su aporte curativo para enfermedades psicosomáticas como la anorexia, la hipertensión, alergias, erupciones, migrañas, úlceras y la colitis o enfermedades como el cáncer. Desde 1987, por ejemplo, fue fundada en Estados Unidos la American Association for Therapeutic Humor. Y hay indicaciones tan específicas como que la risa puede prevenir el anquilosamiento de la artritis, eliminar la tensión y hacer más resistentes a la inflamación los tejidos conjuntivos, así como curar las alergias.
} 
ridad es mayor hasta piernas y pies participan. El corazón se acelera aumentando la circulación; se estimulan otros órganos internos como el páncreas, el hígado y los intestinos por el movimiento de los músculos lisos que rodean estas vísceras. Se puede llegar al llanto o a la pérdida del control de esfínteres. También se multiplica la capacidad pulmonar hasta cuatro veces de lo normal, y el hipotálamo libera mayor cantidad de endorfinas que son analgésicas y producen una sensación de bienestar, aumentando la estimulación cerebral, la creatividad y la agudeza mental. Según recientes estudios neurológicos la risa coadyuva a disminuir la concentración de hormonas causantes del stress, aumenta la flexión muscular y activa la producción de anticuerpos, fortaleciendo el sistema inmunológico. Como dice el Dr. William F. Fry, autor de The Biology of Humor (1993): "reímos con todo nuestro ser".

En su clásico libro La risa, de 1910, Henri Bergson afirma: "La risa es un placer y la humanidad capta al vuelo la menor ocasión para hacerla brotar". La risa castiga las costumbres y tiene una significación social. No es un acto en soledad pues es en el contacto con otras inteligencias que se manifiesta como una complicidad entre sujetos reales o imaginarios. Lo cómico se dirige a la razón y la insensibilidad lo acompaña.

Desde la perspectiva de Bergson, todo lo cómico se reduce a la percepción de un mecanismo en acciones o actitudes cuya naturaleza no es mecánica. La vida fluye en el tiempo y en el espacio, es irreversible y única; cualquier repetición es sospechosa por rígida, predecible e inauténtica. Esta premisa le sirve para explicar porque los movimientos de un cuerpo, los gestos de un rostro, una forma de hablar, la torpeza, ciertas actitudes o acciones son irrisorios en la medida en que nos parecen mecánicos, reiterativos y susceptibles de ser imitados.

Antes que él, Kant la describió como una emoción que lo mismo brinda placer al espíritu por el "súbito aniquilamiento de una espera intensa" que proporciona bienestar corporal por 
el relajamiento de los intestinos. La risa surge en el momento en que una expectativa intensa llega a su fin sin ser colmada.

Freud aportó con su famoso ensayo "El chiste y su relación con lo inconsciente", de 1905, y otro menos frecuentado, "El humor" de 1928, toda una teoría psíquica sobre esta emoción, cuya fuente de placer reside en el ahorro del despliegue afectivo. Ve en el chiste semejanzas con el sueño; pero mientras este último se encamina predominantemente al ahorro de displacer, el primero se dirige a la consecución de placer. "Sin duda la esencia del humor consiste en que uno se ahorra los efectos que la respectiva situación hubiese provocado normalmente eludiendo mediante un chiste la posibilidad de semejante despliegue emocional". 8

También Freud enalteció al humor como una más de las estrategias del aparato psíquico para eludir el sufrimiento.

Lo grandioso reside, a todas luces en el triunfo del narcisismo, en la victoriosa confirmación de la invulnerabilidad del yo. El yo rehusa dejarse ofender y precipitar al sufrimiento por los influjos de la realidad; se empecina en que no pueden afectarlo los traumas del mundo exterior; más aún: demuestra que sólo le representan motivos de placer. ${ }^{9}$

En México el filósofo Jorge Portilla reflexionó sobre el relajo, el humor y la risa. Portilla cuestiona los estudios que no han abordado el qué de la risa, sino que la han visto sólo como

8 "Para comprender la génesis del placer humorístico, lo mejor es considerar el proceso que se opera en el oyente ante quien otra persona despliega su humor. Aquél ve a ésta en una situación cuyas características le permiten anticipar que producirá las manifestaciones de algún afecto: se enojará, se lamentará, expresará dolor, susto, terror, quizá aun desesperación, y el espectador oyente se dispone a seguirla, a evocar en sí las mismas emociones. Pero esta disposición afectiva es defraudada, pues el otro no expresa emoción alguna, sino que hace un chiste. En el oyente surge así, del despliegue afectivo ahorrado, el placer humorístico."("El humor", en Obras completa de Sigmund Freud, p. 248.)

${ }^{9}$ Ibidem. 
una consecuencia de lo mecánico, lo cómico, el inconsciente o lo metafísico, explicaciones que sólo pretenden la confirmación de una teoría.

Partiendo de la propuesta de Alfred Stern, para quien la risa es un juicio de valor negativo que de forma instintiva se ejerce ante una degradación de valores, Portilla formula su propia definición:

La risa sería entonces una forma de conciencia que, ante la degradación del valor y justamente por esta degradación trataría de asegurarse a sí misma su libertad frente a tal degradación y a asegurar, al mismo tiempo, el carácter invulnerable del mundo del valor en general. La estructura intencional de la risa sería la de un "sí... pero", expresado con una violencia corporal cuyo sentido último sería el de gozar con el propio cuerpo la estabilidad del mundo del valor. ${ }^{10}$

\section{Para fascinar al espíritu}

Recientemente la investigadora Carmen Leñero ${ }^{11}$, en su texto titulado "Teatralidad y percepción" escribió sobre la relación entre resultados experimentales de estudios neurológicos y lo teatral, pues encuentra en esos ejemplos posibles conexiones que permiten explicar la dinámica espectacular del teatro. Los casos clínicos registrados por el Dr. V. S. Ramachandran (Director del Centro del Cerebro y la Cognición en la Universidad de California), sirven a la investigadora para asociarlos al fenómeno de lo teatral y la percepción del mismo. Me limitaré a referirme al ejemplo del paciente a quien duele un brazo amputado y siente alivio al mostrarle en un espejo el otro miem-

\footnotetext{
${ }^{10}$ Jorge Portilla, Fenomenología del relajo y otros ensayos, p. 47.

${ }^{11}$ Fractal 20, pp. 23-38.
} 
bro. El dolor cesa, se consigue el alivio a través de esta escenificación en el espejo. El enfermo sabe que se trata de un espejo, no obstante su cerebro "se deja engañar"; acepta "como bueno" el reflejo, y esta percepción sensorial a través de la vista se traduce en un bienestar físico. "Porque saber y ver son cosas muy distintas. La ilusión teatral lo demuestra, pues en su ámbito los espectros se dan a ver, y de una manera primitiva pero fascinante, después de perturbarnos se disuelven". ${ }^{12}$

Por lo que toca al teatro, estos estudios sobre la percepción abren la posibilidad de que una representación pueda tener un sentido de realidad y validez, de ahí que el fenómeno teatral pueda transformar al hombre en tanto experiencia positivamente vivida. ¿Qué pasa cuando se asiste a una comedia? ¿Qué ocurre si lo que se percibe es un enredo amoroso, el tropezón de un cómico, la suplantación de personalidad? ¿Qué se siente al escuchar injurias verbales, bajezas que agreden los valores propios ?

Ir al teatro a reír puede transformar al espectador y no únicamente porque lo expuesto en la escena lo lleve a la reflexión y lo relaje, sino por la experiencia de gozo que lo cómico implica.

La capacidad curativa que hoy, como ya antaño, la ciencia confiere a la risa, está directamente asociada a la producción de endorfinas, a la reducción de tensión muscular y de hormonas asociadas al stress. Pero cabe preguntarse ¿qué hay antes de la carcajada? Son tantos los elementos involucrados en un acto tan sofisticado de la mente humana que no pretendo dar una respuesta a ello, simplemente me detendré en cinco aspectos asociados a la comicidad teatral.

\section{Anestesia al corazón}

Bergson exige para reír un corazón temporalmente insensible porque la emoción es el mayor enemigo de la risa. Basta ver la

12 Ibidem, p. 25. 
vida con indiferencia para que muchos dramas se vuelvan comedias, explica. Pero ¿por qué la necesidad de esta indiferencia? Porque la simpatía nos vuelve frágiles; porque identificarnos nos conduce al temor por nosotros mismos, y el miedo - si bien bajo control puede ser una emoción agradable para algunos- no es camino al placer.

La comedia y la farsa amplían la distancia, mostrando personajes que permiten al espectador sentirse física, social o moralmente superior, y tejiendo tramas de las que el público está a salvo, entretenido e interesado pero bajo resguardo. Así, desde su butaca el espectador piensa: "Ése que está en escena no soy yo. Yo no podría estar en un enredo así”.

\section{Suspensión del juicio}

La risa siempre implica una transgresión. Es preciso que el público se libere de sus prejuicios y convenciones, que abandone la lógica de la razón para que opere la lógica de la imaginación. Como en los chistes, lo cómico radica más en el cómo que en el qué, es decir, en la forma específica en que el diestro humorista lo ha construido.

Para Freud, la tendencia y la función del chiste consiste en proteger de la crítica las conexiones verbales e ideológicas productoras del placer; es decir, bajar la guardia del juicio y las inhibiciones. En ese sentido, las articulaciones mecánicas con que se presentan los acontecimientos cómicos, esto es, las frases, tics, movimientos y escenas que se repiten, los juegos verbales, los equívocos o la inversión de papeles, los personajes títere, la situación que crece fuera de control como una bola de nieve, el burlador burlado, el desarrollo simétrico del quid pro quo, entre otros, son los recursos teatrales para provocar la risa. En todos ellos hay una rigidez y una repetición que traiciona el devenir siempre imprevisible de la vida. 
Otro tanto ocurre con la parodia, la caricatura y la exageración, todas ellas formas de reconquistar el placer del disparate. El gozo de repetir palabras sin sentido como en la primera infancia, es rechazado tan pronto se adueña de nosotros la razón. Los juicios lógicos nos dicen que esos juegos carecen de sentido. Pero los desatinos de palabra y actos del comediante, así como el tratamiento fársico de una escena teatral nos devuelve la gratificación de ese acto irracional, lo que es más aún, adormecen nuestro juicio para que el individuo regrese a un estado de juego y permisión.

Las asociaciones mentales inconscientes nos llevan a mantener fijas algunas relaciones; el absurdo disocia los elementos que por lo regular van unidos, al mismo tiempo que asocia elementos de diferentes contextos, mostrando así nuevas relaciones y acortando distancias de otro modo insalvables.

\section{Flexibilidad que evidencia la rigidez.}

Al mismo tiempo que lo risible lleva implícito un procedimiento mecánico, su producción y recepción precisan de una soltura extrema: flexibilidad del comediante, quien controla su cuerpo y su voz al grado de obligarlos a encarnar la dureza y la torpeza del cuerpo de su personaje - que por lo general simboliza la estrechez de un espíritu o una sociedad (vienen a mi mente Buster Keaton, Chaplin, Mr. Bean, Cantinflas, Tintán, Héctor Ortega); flexibilidad del dramaturgo y el director, quienes enfrentan el drama de la vida, los vicios de la sociedad, los desajustes de los individuos, y extienden ante nuestros ojos otra cara del prisma que vuelve inevitable poner en tela de juicio todos nuestros valores, porque todo es relativo, perfectible, mudable; flexibilidad, en fin, que nos enfrenta a nuestra rigidez, que suaviza la existencia. ${ }^{13}$

\footnotetext{
${ }^{13}$ Este principio de flexibilidad puede estar asociado a la reversibilidad de la comedia; los muertos pueden volver a ponerse en pie; un maleficio puede
} 
El reino del cuerpo.

Lo cómico pide un extremo trabajo actoral y una particular pericia de los movimientos corporales, porque lo cómico es asunto de este mundo y ocurre en un cuerpo. Por ello su constante alusión a lo material y contingente: al cuerpo que tropieza o envejece, a la comida, al sexo, a lo escatológico, todo lo relacionado con el bajo vientre.

Lo cómico nos remite siempre a la mortalidad no a lo eterno. Devuelve al hombre siempre a su condición humana, corpórea y efímera; no se ocupa de su espíritu o su trascendencia a menos que sea para refutarlos. Lo sublime, lo perfecto, lo divino, lo inasible no son objetos de mofa; sólo su caída de ese "estado de gracia" permite su desacralización, su ridiculización. Se dice que los hombres iluminados no ríen a carcajadas, tan sólo sonríen condescendientemente, con un sereno sentido del humor.

Los hombres comunes reímos y todos nuestros miembros, órganos y aun algunas glándulas participan de esta emoción que se manifiesta inequívocamente en nuestro cuerpo.

\section{La agresión}

Parece que toda comicidad lleva implícito cierto grado de agresividad, sin embargo, lejos de ser un signo de barbarie, es una forma sofisticada de civilización. En el orden provisional que "el mundo al revés" de las fiestas medievales instauraba, la mofa, la violencia y lo grotesco tenían su bien merecido lugar. El carnaval era la ocasión precisa para que todos los instintos afloraran, sin represión ni distinciones, bajo el tono de la fiesta y el entierro del mal humor.

revertirse; nada de lo que pasa se presenta como definitivo. La historia no es lineal sino circular. 
En toda representación teatral podemos asistir a una demostración de la violencia, pero será particularmente en la comedia y más aún en la farsa donde nuestro instinto agresivo se vea reflejado, y en lugar de ser juzgado se permita su expansión. La comedia, la farsa y la tragicomedia son, pues, complejos mecanismos sociales que dan salida a los instintos.

En el teatro cómico la agresión debe conducir a la risa, y cuando no llega hasta ella, la temporal anulación del juicio y la anestesia al corazón nos permiten percibir y vivir la violencia sin ponernos en riesgo, pero permitiendo que experimentemos la satisfacción de nuestros naturales instintos de agresión.

Cuando se refiere a la sonrisa, insinuación o preámbulo de la risa, Freud ve en este gesto el pliegue de los labios del lactante satisfecho, quien parece decir con placidez "es suficiente". Por otra parte, la risa semeja la expresión agresiva de los mamíferos que enseñan los dientes para amedrentar al adversario. Esta última actitud, al trastocarse en sonrisa o carcajada, es muestra de una violencia que cambia de curso y se convierte en signo de amistad. Habiendo mitigado el miedo, la experiencia del humor no nos ofrece un mundo perfecto pero sí nos habilita para sobrellevarlo al relativizar su gravedad e inalterabilidad.

El teatro puede transformarnos, puede regalarnos la experiencia del placer y de un conocimiento a la vez ficticio y veraz de la realidad. Para Artaud, "el espíritu cree lo que ve y hace lo que cree: tal es el secreto de la fascinación".

Al igual que el sueño, el sentido del humor aligera el peso diario de nuestras responsabilidades, la conciencia de nuestra fragilidad, el esfuerzo que implica establecer y mantener los lazos que nos unen a los otros, el miedo al ridículo y a la reprobación de nuestros actos. Sólo el humor nos permite dar la medida justa a las cosas y relativizar su importancia. En el caso de la comedia y la farsa, al menos en lo que dura la representación, habremos de divertirnos, de entretener el espíritu, 
esto es, de alejar su atención de la gravedad que hemos conferido a la existencia, para descansar de nosotros mismos y gozar sin temor.

\section{Bibliografía}

Bentley, Eric, La vida del drama, Paidós, Buenos Aires, 1964.

Freud, Sigmund, "El humor", en Obras completas t. XXI, Santiago Rueda, ed., Argentina, 1955.

Garanto Alós, Psicología del humor, Herder (Biblioteca de psicología, núm. 113), Barcelona, 1983.

Leñero, Carmen, “Teatralidad y percepción”, Fractal 20, 2001, pp. 23-38.

Portilla, Jorge, Fenomenología del relajo y otros ensayos, México, FCE/CREA (Col. Biblioteca Joven), 1984.

Rabelais, François, Gargantúa y Pantagruel, Bruguera, España, 1971. 